\title{
Alfabetização e analfabetismo no Brasil: algumas reflexões
}

\author{
Literacy and illiteracy in Brazil: some reflections \\ Alphabétisation et analphabétisme au Brésil: \\ quelques réflexions
}

Jacqueline de Fátima dos Santos MORAIS

Mairce da Silva ARAÚJO

\section{RESUMO}

Este artigo apresenta algumas reflexões acerca da alfabetização no Brasil ao longo do tempo. Para tanto, utiliza a existência de leis a favor da alfabetização, passagens de romances, pesquisas feitas sobre e temática e ainda depoimentos de educadores. $\mathrm{O}$ artigo mostra a tendência do pouco que é oferecido aos mais pobres ao longo da história brasileira.

Palavras- chave: alfabetização, Brasil, pobreza.

\section{ABSTRACT}

This article presents some reflections concerning the literacy in Brazil throughout the time. In such a way, it uses Brazilian's laws in favor of the literacy, romances, research made about this thematic and teacher's words. The article shows the little that is offered to poor Brazilians throughout Brazil's history.

Index terms: literacy, Brazil, poverty.

\section{RESUME:}

Cet article présente quelques réflexions concernant l'alphabétisation au Brésil au long du temps. De telle façon, il utilise l'existence de lois en faveur de l'alphabétisation, passages de romances, recherches faits sur cette thématique et encore des mots des éducateurs. L'article montre la tendance du peu qui est offert aux plus pauvres au long de l'histoire brésilienne.

Mots clés: alphabétisation, Brésil, pauvreté. 


\section{Introdução}

\section{Do passado...}

A temática da alfabetização encontra-se na pauta de discussão de importantes fóruns, órgãos e instâncias no Brasil. Este interesse não representa uma novidade, bem o sabemos. Ao olharmos a história da educação nacional, encontramos pistas sobre como o tema vem sendo tratado há muito neste país. Saviani (2002) nos lembra que em 15 de outubro de 1827 foi promulgada a primeira Lei que determinava a criação de escolas de primeiras letras. É em alusão a importância dessa data que temos comemorado, no Brasil, o dia do professor.

A referida lei estabelecia que nas escolas criadas, os professores ensinariam

a ler, escrever, as quatro operações de aritmética, prática de quebrados, decimais e proporções, as noções mais gerais de geometria prática, a gramática da língua nacional, os princípios de moral cristã e de doutrina da religião católica e apostólica romana proporcionadas à compreensão dos meninos. ${ }^{1}$

Este regulamento, no entanto, não garantiu, na prática, a instalação de escolas elementares em todas as cidades, vilas e lugares populosos. (BRASIL, 1827). Em 1834 um Ato Adicional à Constituição do Império desobrigou o governo central de cuidar das escolas primárias e secundárias, transferindo essa incumbência aos governos provinciais. O resultado, afirma ainda Saviani (2002), foi a falta de investimentos na abertura de escolas e o adiamento da alfabetização da população brasileira.

\footnotetext{
${ }^{1}$ Artigo $6^{\circ}$ do Decreto Imperial de 15/10/1827.
} 
Vemos assim que a tematização da alfabetização e a fragilidade das ações oficiais em favor da aprendizagem da leitura e da escrita para toda a população não é algo novo neste país.

\section{Do presente e seus instrumentos de medida}

Mais recentemente temos visto, lido e discutido (ESTEBAN, 2008; OLIVEIRA e ARAUJO, 2005, FREITAS, MALAVAZI e BERTAGNA, 2006; FRANCO, 2006) a respeito da divulgação dos baixos índices alcançados por estudantes brasileiros em testes de proficiência de leitura e escrita. Dentre estes exames, podemos relacionar: Provinha Brasil, ENEM, SAEB, ENADE, PISA. Cada um deles se dirige a um grupo diferenciado de estudantes e, portanto, a uma faixa etária específica que vai das classes iniciais de escolaridade aos cursos universitários, como no caso do Exame Nacional de Desempenho dos Estudantes, ENADE, que pretende avaliar o ensino superior brasileiro e que, desde 2004, substitui o chamado Provão.

Até agora, o único nível que não sofreu formalmente uma medição de níveis de aprendizagem foi a educação infantil. Não sabemos até quando as crianças de zero a seis anos serão poupadas, mas é certo que alguns países já adotam critérios de avaliação para esta etapa da escolaridade. Sabemos também que os organismos internacionais como Banco Mundial tem pressionado diferentes governos para que indicadores de qualidade possam ser estabelecidos oficialmente e, assim, haver algum tipo de controle sobre verbas e apoios financeiros dados por esses órgãos financiadores (Cf. ROSEMBERG, 2001).

Os resultados das avaliações referentes aos diferentes níveis e etapas da educação brasileira parecem anunciar, há algum tempo, uma mesma conclusão: alunas e alunos brasileiros pouco compreendem daquilo que lêem. O que significa dizer que poucos dominam a língua que usam. 
Os últimos dados divulgados a respeito da Prova Brasil, por exemplo, sistema que avalia alunos da $4^{\mathrm{a}}$ e $8^{\mathrm{a}}$ série, mostram que em 2007 , se comparado o desempenho de matemática e português, esta última área de conhecimento perde para a primeira nos dois anos de escolaridade avaliados. A média alcançada pelos alunos da $4^{\mathrm{a}}$ série (hoje chamado de $5^{\circ}$ ano de escolaridade) foi de 171,40 em português, enquanto que na prova de matemática a média brasileira ficou em 198,14. Se analisarmos os dados referentes à $8^{\text {a }}$ série (atual $9^{\circ}$ ano) vamos encontrar como média nacional 228,93 em língua portuguesa, enquanto que a média relativa à matemática ficou em 240,56. Ou seja: nossos alunos e alunas têm tirado notas piores em português do que nas avaliações referentes à matemática.

Assim, mais uma vez, retornamos a discussão sobre leitura, escrita e compreensão textual. Invariavelmente, voltamos a temática da alfabetização: daquela que parecemos ter e daquela que gostaríamos de construir.

Se em relação aos instrumentos oficiais de medição de aprendizagem podemos produzir inúmeras críticas a respeito de sua validade, eficiência e eficácia como instrumento avaliativo, não podemos, no entanto, negar a existência dos dados gerados. E nem negar que eles falam. Mas aí reside a questão: o que eles falam? Ou, dito de outra forma: o que nós ouvimos dos dados que vemos?

Uma das coisas que podemos ouvir desses dados é que ensinar a ler e escrever a todos continua sendo um grande desafio para a escola e para os sistemas de ensino. Dados oficiais divulgados pelo Ministério da Educação - MEC - apontam a quase universalização da educação básica. O Ministério da Educação através do INEP, Instituto Nacional de Estudos e Pesquisa, aponta taxas de mais de $93 \%$ de matrículas escolares referentes às crianças 
de sete aos 14 anos. A questão, então não estaria no acesso à escola, mas em outros fatores. Quais seriam estes, então?

Se o problema, a princípio, não se concentra na impossibilidade de haver vagas para a totalidade das crianças nos sistema de ensino, nosso foco se volta para a permanência dos alunos e alunas nas escolas.

Dados também do MEC nos dão a dimensão do problema. Segundo o INEP (2003), temos um total de 31.733.198 alunos no ensino fundamental, mas este número cai vertiginosamente para 8.264.816 quando contabilizados somente aqueles que se encontram no ensino médio. Os dados nos mostram, portanto, que o problema não está em garantir o acesso dos alunos à escola fundamental, mas na capacidade das escolas, dos sistema de ensino e da sociedade em criar formas de permanência e continuidade dos estudos desses brasileiros.

Assim, a taxa de atendimento, de aproximadamente, 93\%, relativa aos anos iniciais de escolaridade, cai para $49 \%$ quando referente ao atendimento para o ensino médio. Há vários estudos que buscam compreender esse estado. Aqui não vamos nos ater a essa discussão; queremos, isto sim, centrar nossa análise nas possíveis pistas que nos levem a entender porque tantos alunos e alunas parecem não se apropriarem da leitura e da escrita.

\section{Porque não se alfabetiza, então?}

$\mathrm{Na}$ busca por compreender o passado, pois que este traz pistas para compreendermos o presente, vamos em direção a literatura. Esta é rica em exemplos de como era o tratamento dado ao ensino da língua e de como ainda hoje vivemos seus dilemas. 
Ao descreverem as práticas pedagógicas testemunhadas ou mesmo sofridas no tempo escolar, certos autores acabam por denunciar concepções e paradigmas hegemônicos de um tempo que, em alguns casos, parece não ter ficado para trás. Algumas dessas práticas e concepções ainda habitam o cotidiano das classes de alfabetização país afora, resultando em um ensino centrado na cópia, na repetição e na memorização. E claro, nos testes e provas como estratégia de medição do que foi "aprendido". Esse tipo de educação há muito foi denunciado por Freire (1997, p. 27 e 28), na idéia da educação bancária. Apesar das críticas apontadas por Freire a respeito da concepção de educação bancária, esta ainda é bastante comum no interior das escolas e dos sistemas de ensino.

Vamos encontrar nas memórias de Graciliano Ramos, a exemplificação do que Freire denuncia. Em seu livro Infância (2003), publicado pela primeira vez em 1945, o autor de Vidas Secas e Memórias do Cárcere, dentre outros importantes livros, descreve como foi seu contato com as primeiras letras quando criança. Gritos, ameaças, castigos, palmatória, acompanharam o menino Graciliano durante as aulas que seu pai, homem rude e de didática espartana, insistia em ministrar. Era um aprendiz sem entusiasmo, tendo a sua frente como material impresso, uma cartilha de capa enfeitada por três faixas verticais, de páginas amarelas e papel ordinário, de letras mal impressas a se esfarelar por entre os dedos que teimavam em embeber-se de suor. Graciliano nos conta o tortuoso processo de aprendizagem das letras do alfabeto. Quando lhe parecia haver aprendido todas as letras, novas surgiam, numa seqüência que parecia não ter fim.

Enfim consegui familiarizar-me com as letras quase todas. Aí me exibiram outras vinte e cinco, diferentes das primeiras e com os mesmos nomes delas. Atordoamento, preguiça, desespero, vontade de acabar-me. Veio terceiro alfabeto, veio quarto, e a confusão se estabeleceu, um horror de qüiproquós. 
Quatro sinais com uma só denominação. Se me habituassem às maiúsculas, deixando as minúsculas para mais tarde, talvez não me embrutecesse. Jogaram-me simultaneamente maldades grandes e pequenas, impressas e manuscritas. Um inferno (RAMOS, 2003, p. 97).

$\mathrm{O}$ que denuncia Graciliano com sua história? O que essa narrativa revela sobre como temos, ao longo do tempo e ainda hoje, ensino a ler e escrever?

Rememorando a própria infância, Graciliano (2003, p. 99) nos leva a conhecer seu universo, por um lado tão pessoal, por outro tão próximo de tantos e tantas de nós. Neste outro episódio encontramos uma criança diante das páginas finais da cartilha. O texto, lido penosamente por Graciliano, parecia não lhe fazer sentido algum.

A preguiça é a chave da pobreza.

Quem não ouve conselhos raras vezes acerta.

Fala pouco e bem: ter-te-ão por alguém.

Quem seria Terteão? O que fazia na página final da cartilha? As perguntas de Graciliano não encontravam respostas. Nem em si nem em sua irmã mais velha. Também ela não conhecia Terteão. Sequer havia pensado tratar-se de um homem. E assim, Graciliano criança, fora jogado ao mundo da leitura. Tornou-se o escritor que é. Apesar de tudo que viveu.

É isto que nos leva, de um lado, à crítica e à recusa ao ensino bancário, de outro, a compreender que, apesar dele, o educando a ele submetido não está fadado a fenecer, em que pese o ensino bancário, que deforma a necessária criatividade do educando e do educador, o educando a ele sujeitado pode, não por causa do conteúdo cujo conhecimento lhe foi transferido, mas 
por causa do processo mesmo de aprender, dar como se diz na linguagem popular, a volta por cima e superar o autoritarismo e o erro epistemológico do bancarismo (FREIRE, 1997, p. 27 e 28).

Graciliano conseguiu superar a educação autoritária, venceu a concepção bancária que denuncia Freire e o analfabetismo funcional, tornando-se um grande escritor. Muitos não têm esse mesmo destino - pelo menos 16.295 milhões de pessoas no Brasil são incapazes de ler e escrever pelo menos um bilhete simples de acordo com INEP (2003). Se incluirmos as pessoas com menos de quatro séries de estudo concluídas, os chamados analfabetos funcionais, o total salta para 33 milhões. Os dados, mais uma vez retirados do Mapa do Analfabetismo no Brasil, nos convidam a pensar.

São Paulo é a campeã em números absolutos: são mais de 383 mil pessoas a quem o direito a leitura e escrita foi negado. No Rio de Janeiro, são quase 200 mil.

Em apenas 19 dos 5.507 municípios do país a média de escolarização dos moradores corresponde a oito anos, ou seja, o ensino fundamental completo (de $1^{\mathrm{a}}$ a $8^{\mathrm{a}}$ série), um direito determinado por lei a todos.

A cidade com o maior índice de escolaridade é Niterói, no Rio de Janeiro. Nela a média é de 9,5 séries concluídas, enquanto que em Guaribas, no Piauí, encontramos a pior colocação, 1,1 ano de estudo. Mas freqüentar a escola não é garantia de aprendizado: 7,4\% dos adolescentes de 10 a 19 anos não sabem ler e escrever.

Esses jovens ou ainda estão na escola ou por ela já passaram, o que mostra que nosso sistema educacional continua a produzir analfabetos (INEP, 2003, p. 10). 
Mas há também os que freqüentaram uma escola e a abandonaram, por motivos diversos.

É doloroso constatar que, no Brasil, 35\% dos analfabetos já freqüentaram a escola. As razões para o fracasso do País na alfabetização de seus jovens são várias: escola de baixa qualidade, em especial nas regiões mais pobres do País e nos bairros mais pobres das grandes cidades; trabalho precoce; baixa escolarização dos pais; despreparo da rede de ensino para lidar com essa população (INEP, 2003, p. 10)

$\mathrm{Ou}$ seja, todos estes dados indicam que os debates sobre alfabetização não foram esgotados. Nem tampouco as pesquisas e investigações conseguiam encerrar nossas preocupações. Ao contrário: há muito que fazer e muito que ainda indagar.

Assim, poderíamos nos perguntar diante dos dados resultantes das inúmeras pesquisas (oficiais ou não): quem são os alunos que estão fracassando de forma tão brutal na escola? Quem constitui a parcela dos que foram muito bem nos diferentes sistemas de avaliação? E os que foram muito mal, quem são? O fracasso ou o sucesso escolar são distribuídos de maneira equivalente entre as diferentes camadas sociais?

As perguntas parecem ficar no ar quando olhamos apenas os dados estatísticos isolados da conjuntura mais ampla. É preciso olhar os dados e a história do fracasso escolar à contrapelo, como nos convida Benjamin (1996) para, quem sabe, desconfiar das conclusões a que chegam o SAEB e o PISA: a de que o fracasso é culpa de quem está na escola. É preciso desnaturalizar nosso olhar para nos perguntarmos, como Freire (2001) sempre fez: $\square$ a serviço de que e de quem fazemos o que fazemos em educação? $\square$

\section{Considerações finais}


Temos defendido que é preciso compreender o fracasso escolar de maneira mais complexa (Cf. MORIN, 1995), o que supõe vê-lo como a produção de um fracasso social, e não como resultado de um malogro individual. Para isso basta olharmos aqueles que não aprendem a ler e escrever - são, em sua grande maioria, oriundos das camadas mais pobres da população. Isso significa que o fracasso escolar não está distribuído democraticamente por todos os segmentos da população, mas se encontra concentrado em um mesmo grupo social. Sempre o mesmo grupo. Coincidentemente os mais pobres.

Numa sociedade onde ler e escrever representa poder, aqueles que não sabem interpretar um texto ou registrar por escrito suas próprias palavras acabam por ser subalternizados (Cf. LANDER, 2005). Falar de analfabetismo, portanto, seja ele produzido no interior das escolas ou fora delas, é falar de uma injustiça social. Falar de analfabetismo é denunciar as injustiças que produzem a desigualdade, pois $\square$ não cabe fatalisticamente cruzar os braços $\square$ (FREIRE, 2001, p. 98).

Alfabetizar todos continua a ser um projeto e um desafio. E este desafio não é apenas para a professora ou para a criança. Este é um desafio coletivo, social. Ou deveria ser. No entanto existem no mundo cerca de 113 milhões de crianças fora da escola. Por que não nos indigna esse número? Talvez por esquecermos que atrás destes números há nomes: Helena, Pedro, Tereza, Luiz, Raquel, Sonia, João, Flavia, Amanda... Os números escondem sujeitos reais, pessoas que possuem sonhos e vontades.

Desta forma, adverte ainda Garcia (2008, p. 566), que é preciso

(....) refletir crítica e coletivamente sobre as conseqüências sociais, culturais e políticas na vida de quem passa pela escola e dela sai, tantas vezes ao 
final do tempo de escolaridade obrigatória, sem sequer saber ler e escrever.

Mais uma vez encontramos a idéia de que alfabetizar implica compromisso político muito mais que mero empenho técnico ou metodológico. Para quê, para quem, por que alfabetizamos? Estas são perguntas fundamentais e que apontam concepções epistemológicas que são, como já nos dissera antes Freire (1997), políticas. As opções metodológicas são decorrência daquelas.

Alfabetizar não é ensinar a decodificar letras em sons, apesar de ser ainda uma concepção hegemônica. Estamos nos alfabetizando permanentemente, se entendermos alfabetização no sentido que lhe dá Paulo Freire: leitura do mundo que implica leitura da palavra. E leitura da palavra que provoca e amplia leitura do mundo.

A falta de políticas educacionais sérias, que caminhem para além da mera constatação dos problemas, mas que apontem propostas para superação dos aspectos que produzem o fracasso, estão longe de acontecer. De tão repetido, parece uma velha retórica, desgastada pelo tempo e pelos modismos, entretanto, é preciso continuar a dizer que necessitamos garantir uma escola de qualidade para as crianças e jovens, especialmente aqueles das camadas mais pobres da população. Dizer que é preciso resolver as más condições físicas das escolas; a falta de professores, a ausência de segurança; a falta de bibliotecas, a falta de conservação dos prédios escolares, as dificuldades de acesso aos bens culturais presentes na cidade.

Saímos de um momento no qual a centralidade nas discussões era o método de alfabetização. Durante décadas ficamos entre definir se os sintéticos - aqueles que partem das menores unidades da língua, letra, som, sílaba - ou os analíticos - aqueles que começam pelas unidades maiores da língua, frases, orações, contos - seriam os mais eficientes. Terminamos a 
chamada querela dos métodos (Cf. BRASLAVSKY, 1971) sem a definição. Os chamados métodos ecléticos passaram a ser vistos como uma opção, já que prometiam trazer o que de melhor houvesse em um e outro. Também essa promessa foi uma querela.

Na década de oitenta, com a entrada no Brasil dos estudos de Emília Ferreiro, colocou-se outro foco nos debates sobre alfabetização. As discussões que tinham como centralidade a pergunta: como o professor ensina; passaram a focar a pergunta: como a criança aprende. Essa mudança provocou inúmeras outras pesquisas e discussões. O certo é que o trabalho de Ferreiro ampliou nosso olhar sobre as razões pelas quais crianças e jovens não se alfabetizam. O trabalho desta autora, mesmo que com inúmeras críticas e limites, instiga-nos a pensar que a questão é complexa. Simplificá-la como temos feito não tem ajudado a transformar o quadro que temos.

A aposta que as famílias fazem na educação de seus filhos mostra que a escola é também vista como lugar de potencialização e não apenas, como querem alguns, lugar de discriminação e exclusão. Neste sentido poderíamos nos perguntar: a quem interessa que a escola seja vista apenas como lugar de produção de fracasso escolar? A quem interessa a produção de pesquisas e a divulgação de dados que apontam as classes populares como culpadas de seu próprio fracasso? A quem interessa a fabricação de investigações que resultam na subalternização dos saberes das classes populares?

Um flash do cotidiano escolar ${ }^{2}$ pode contribuir para colocarmos mais uma vez em questão as concepções político-epistemológicas que

\footnotetext{
${ }^{2} \mathrm{O}$ exemplo em questão foi apresentado originalmente no artigo "Provinha Brasil: mais uma resposta simplificada para o problema do fracasso escolar" por Mairce Araújo conforme consta na bibliografia deste artigo.
} 
fundamentam a escolha do instrumento Prova como um referencial seguro para aferir o desempenho escolar das crianças de seis a oito anos em relação ao domínio da língua escrita.

Trazemos um trecho da monografia de Michele Vicente da Silva (2007), apresentada ao Curso de Especialização Alfabetização das crianças das classes populares, na Universidade Federal Fluminense. Uma das educadoras presentes no curso, chamada aqui de Michele, conta que:

Numa manhã, Adilson chegou à sala chorando, porque queria dormir e sua mãe não deixou que ele ficasse em casa. Conversei com ele sobre a importância de estudar, que quando ele não vem, a sala de aula não é a mesma. E ele disse que não agüentava mais, e que, queria muito, matar sua irmã caçula. Disse que passava quase todas as noites em claro tomando conta da menina, que ela chorava muito. E que no dia anterior, havia ficado a noite toda balançando ela no colo para que dormisse, e ela só chorava, vindo a dormir por volta das cinco horas da manhã, quando finalmente ele pode dormir também. Mas logo, às seis da manha, sua prima o havia acordado para ir à escola. Quando perguntei sobre sua mãe ele respondeu que ela estava fazendo o que faz todos os dias "tava morgada na cama tia, bêbada igual a gambá, nem o peito pra menina ela dá”. Fiquei pensando, então sobre o motivo pelo qual a menina ficava chorando durante toda a noite: deveria ser de fome.

Mais adiante, a mesma educadora nos relata:

No dia seguinte à nossa conversa, buscando fazer o que Paulo Freire (1997) chama de vincular linguagem e realidade utilizando como "palavras geradoras" aquelas retiradas do próprio "universo vocabular dos grupos populares expressando a sua real linguagem, seus anseios, as suas inquietações, as 
suas reivindicações, os seus sonhos, resolvemos trabalhar com eles um texto diferente, sem dizer para ninguém o motivo. Propusemos às crianças que escrevêssemos um livro de receitas, e sugerimos que a primeira fosse de um mingau para bebê. As crianças iam falando, íamos discutindo e criando a receita. Depois fomos à cozinha e pedimos para uma das cozinheiras que preparasse o mingau com a receita que havíamos criado. E nossa receita ficou ótima, todos gostaram muito, o Adilson principalmente. E dias depois ele contou que estava preparando mamadeira para sua irmã e ela já conseguia dormir durante a noite.

O relato de Michele nos ajuda a perceber que o desafio cotidiano da prática alfabetizadora dificilmente conseguiria ser medido por qualquer teste padronizado. O que seria possível aferir do desempenho escolar de Adilson antes dele descobrir, orientado por uma professora competente, que o domínio da língua escrita pode lhe trazer novos instrumentos para lidar com a dura realidade com a qual ele vive? Provavelmente, o teste identificaria sua incompetência no domínio da leitura e da escrita e ele iria para a aula de reforço. E o que mudaria para ele ou para tantos outros Adilsons?

Enfim, terminamos este artigo com a seguinte questão: SAEB, Provinha Brasil, PISA, ENEM, e tantas outras siglas que poderíamos acrescentar: afinal, o que todos estes 'exames' têm ajudado a mudar na escola a partir dos resultados que aferiram?

\section{Referências bibliográficas}

ARAÚJO, Mairce da Silva e MORAIS, Jacqueline de Fátima dos Santos. (2007). Alfabetização: desafios da prática alfabetizadora. Revista Eletrônica Acoalfaplp - Acolhendo a Alfabetização nos Países de Língua Portuguesa, v.03, p. 157 - 171.

BENJAMIN, Walter (1996). Obras escolhidas I. Magia e técnica, arte e política. São Paulo: Brasiliense. 
BRASIL. Primeira Lei Geral de educação no Brasil. 15 de outubro de 1827.

BRASLAVSKY, Berta P. de (1971). Problemas e métodos no ensino da leitura. São Paulo: Melhoramentos, EDUSP.

ESTEBAN, M. T. (2008). Provinha Brasil: reeditando a velha confusão entre avaliação e exame. Nuevamerica, v. 118, p. 72-75.

FRANCO, C. (2006). Avaliação em larga escala da Educação Básica: da relevância aos desafios. In: FREITAS, Luiz Carlos de, MALAVAZI, Maria Marcia Sigrist; BERTAGNA, Regiane (Org.). Avaliação: desafio dos novos tempos. Campinas: Komedi, v.2, p. 43-65.

FREITAS, Luiz Carlos de; MALAVAZI, Maria Marcia Sigrist; BERTAGNA, Regiane Helena (Org.) (2006). Avaliação: desafio dos novos tempos. Campinas: Komedi.

FREIRE, Paulo (1997). Pedagogia da autonomia: saberes necessários à prática educativa. São Paulo: Paz e Terra. (2001). Política e Educação. São Paulo: Cortez.

GARCIA, Regina Leite (2008). Mais uma vez alfabetização. In: TRAVERSINI, Clarice; EGGERT, Edla; PERES, Eliane; BONIN Iara (orgs). Trajetórias e processos de ensinar a aprender: práticas e didáticas. Livro 2. Porto Alegre: EDIPUCRS, p. 564- 579.

Instituto Nacional de Estudos e Pesquisas Educacionais Anísio Teixeira (INEP). (2003). Mapa do Analfabetismo no Brasil. Brasília.

LANDER, Edgardo (org.) (2005). A colonialidade do saber: eurocentrismo e ciências sociais - perspectivas latino-ameicanas. Buenos Aires: Clacso.

MORIN, Edgar (1995). Introdução ao pensamento complexo. Lisboa: Instituto Piaget.

OLIVEIRA, R. P. de; ARAUJO, G. D. de (2005). Qualidade de ensino: uma nova dimensão da luta pelo direito à educação. Revista Brasileira de Educação, n 28, p. 5-23.

RAMOS, Graciliano (2003). Infância. Rio de Janeiro: Record. 
ROSEMBERG, Fúlvia (2001). Avaliação de programas, indicadores e projetos em educação infantil. Revista Brasileira de Educação, no16, p. 1926.

SAVIANI, Dermeval (2002). Percorrendo caminhos na educação. Revista Educação \& Sociedade, v.23, nº 81. SP, Cortez; Campinas, dez., p. 273-290.

SILVA, Michele Vicente da. A família no contexto da educação escolar: uma reflexão sobre a prática alfabetizadora e a participação da família no processo escolar. 105 f. Monografia (Especialização)- Universidade Federal Fluminense, Niterói, 2007.

\section{Autoras:}

Jacqueline de Fátima dos Santos Morais

Professora da Faculdade de Formação de Professores da UERJ e do CAPUERJ

Contato: jacquelinemorais@ hotmail.com

Mairce da Silva Araújo

Faculdade de Formação de Professores da UERJ

Contato:mairce@hotmail.com

\section{Como citar este artigo:}

MORAIS, Jacqueline de Fátima dos Santos \& ARAÚJO, Mairce da Silva. Alfabetização e analfabetismo no Brasil: algumas reflexões. Revista ACOALFAplp: Acolhendo a Alfabetização nos Países de Língua portuguesa, São Paulo, ano 5, n. 9, 2010/ 2011. Disponível em: <http://www.acoalfaplp.net>. Publicado em: setembro de 2010 - março de 2011.

Recebido em setembro de 2009./ Aprovado em outubro de 2009.

Sede da Edição: Faculdade de Educação da Universidade de São Paulo - Av. da Universidade, 308 - Bloco A, sala 111 - São Paulo - SP - Brasil - CEP 05508-040. Grupo de pesquisa: Acolhendo Alunos em situação de exclusão social e escolar: o papel da instituição 